\title{
KARAKTERISTIK PENILAIAN INDEKS MAPPING RISIKO RENCANA PENANGGULANGAN BENCANA DAERAH
}

\author{
${ }^{1)}$ Moch. Shofwan, ${ }^{2)}$ Muhammad Malthuf \\ 1) Program Studi Perencanaan Wilayah dan Kota, Universitas PGRI Adi Buana Surabaya \\ ${ }^{2)}$ Universitas Islam Negeri Mataram \\ Email : shofwan.moch@gmail.com
}

\begin{abstract}
Abstrak
Badan Nasional Penanggulangan Bencana selalu merilis indeks mapping nilai perkembangan risiko kebencanaan kabupaten/kota di Indonesia. Indeks mapping risiko tersebut digunakan Pemerintah Daerah sebagai salah satu dasar dalam perencanaan kabupaten/kota dengan tujuan tercapainya pembangunan yang optimal. Tujuan dari penelitian ini yaitu (1) mengidentifikasi indeks mapping risiko daerah, (2) menganalisis sebaran indeks risiko daerah. Metode analisis yang digunakan dalam penelitian ini dibagi menjadi dua tahapan yaitu (1) analisis deskriptif matematis berdasarkan indeks mapping risiko daerah, dan (2) deskriptif eksploratif berdasarkan sebaran indeks risiko daerah. Berdasarkan hasil penelitian bahwa karakteristik nilai indeks risiko daerah dapat diketahui berdasarkan kejadian bencana kemudian dilakukan perhitungan secara matematis berdasarkan Peraturan Kepala Badan Nasional Penanggulangan Bencana sehingga diketemukan penggolongan tiap wilayah dan tiap jenis bencana. Sebaran keruangan indeks risiko daerah di semua kecamatan yang ada di wilayah administratif Kabupaten Tuban masuk kategori zona hijau, kuning, dan merah.
\end{abstract}

Kata Kunci : Indeks Mapping, Sebaran Keruangan, Risiko

\begin{abstract}
The National Disaster Management Agency always releases an index mapping of the value development of disaster risk in districts / cities in Indonesia. The risk mapping index is used by the Regional Government as one of the bases in district / city planning with the aim of achieving optimal development. The objectives of this study are (1) identifying the regional risk mapping index, (2) analyzing the distribution of regional risk indexes. The analytical method used in this study is divided into two stages, namely (1) mathematical descriptive analysis based on the regional risk mapping index, and (2) explorative descriptive based on the distribution of regional risk indexes. Based on the results of the study, the characteristics of the regional risk index value can be determined based on the occurrence of a disaster, then a mathematical calculation is carried out based on the Regulation of the Head of the National Disaster Management Agency so that the classification of each region and each type of disaster is found. The spatial distribution of the regional risk index in all sub-districts in the administrative area of Tuban Regency is categorized as green, yellow and red zones.
\end{abstract}

Keywords : Mapping Index, Spatial Distribution, Risk 


\section{PENDAHULUAN}

Indonesia secara geografis dan geologis sangat berpotensi terjadinya bencana khususnya bencana alam yang dapat menimbulkan korban jiwa serta kerusakan infrastruktur dal lingkungan yang dapat menghambat laju pembangunan nasional. Bencana menjadi sebuah fenomena yang harus terus dikaji mengingat dampak yang diakibatkan sangat besar ketika wilayah tersebut tidak siap menghadapinya (Shofwan, 2008, Zen, 2009).

Daerah mempunyai peran penting dalam hal pengurangan risiko bencana, dengan segala kapasitasnya baik sumberdaya manusianya maupun sumberdaya anggarannya maka sudah seharusnya daerah memiliki dokumen (legal formal) serta kajian kebencanaan secara holistik untuk antisipasi terjadinya bencana.

Penilaian indeks mapping risiko rencana penanggulangan bencana daerah menjadi elemen terpenting bagi kabupaten/kota sebagai salah satu dasar pengambilan kebijakan perencanaan daerah secara optimal, sehingga diharapkan dalam kajian ini menghasilkan indeks mapping serta sebaran risiko rencana penanggulangan bencana daerah.

\section{METODOLOGI}

\section{Metode Pengumpulan Data}

Metode pengumpulan data dilakukan dengan cara :

1) Survei primer merupakan kegiatan pengumpulan data yang dilakukan secara langsung dan memiliki tujuan untuk memperkuat keadaan sebenarnya pada lokasi penelitian. Dokumentasi adalah mengumpulkan data dengan cara mengambil data-data dari catatan, dokumentasi, administrasi yang sesuai dengan penelitian terkait.

2) Survei sekunder merupakan pengumpulan data dilakukan dengan cara survei instansi terkait dengan pengambilan data melalui instansi pemerintahan, maupun instansi swasta yang berkaitan dengan penelitian ini sangat dibutuhkan guna memperkuat data-data yang belum tersedia pada publikasi masyarakat.

\section{Jenis dan Sumber Data}

Berdasarkan jenis data dibagi menjadi dua yaitu :

1) Data Kuantitatif, yaitu data yang terbentuk angka. Data yang diperoleh adalah ancaman, kapasitas, dan kerentanan.

2) Data kualitatif, yaitu data yang terbentuk dalam bentuk kata-kata, kalimat. Data yang diperoleh adalah peta sebaran indeks.

Dalam penelitian ini pengumpulan data di dapat melalui dua jenis data yaitu :

1) Data primer, sumber data yang diperoleh dari hasil penelitian langsung.

2) Data sekunder, sumber data yang diperoleh sebagai pendukung penelitian ini diperoleh dari instansi terkait yaitu BPS Kabupaten Tuban, BPBD Tuban, dan BAPPEDA Tuban.

\section{Metode Analisis Data}

Metode analisis dalam penelitian penilaian indeks mapping risiko rencana penanggulangan bencana daerah yaitu :

1. Analisis karakteristik kawasan dengan menggunakan metode analisis deskriptif kuantitaif bertujuan untuk mengidentifikasi karakteristik kawasan risiko bencana.

\section{HASIL DAN PEMBAHASAN Gambaran Umum Lokasi}

Kabupaten Tuban merupakan salah satu kabupaten di Provinsi Jawa Timur yang terletak di Pantai Utara Jawa Timur. Kabupaten Tuban terletak pada koordinat $111^{\circ} 30^{\prime}-112^{\circ} 35^{\prime}$ BT dan $6^{\circ} 40^{\prime}-7^{\circ} 18^{\prime}$ LS. Kabupaten Tuban berbatasan dengan Laut Jawa di sebelah utara, Kabupaten Lamongan di sebelah timur, Kabupaten Bojonegoro di sebelah selatan, serta Provinsi Jawa Tengah di sebelah barat. Luas wilayah daratan Kabupaten Tuban adalah $1.839,94 \mathrm{Km}^{2}$ dengan panjang pantai $65 \mathrm{Km}$ dan luas wilayah lautan sebesar $22.608 \mathrm{Km}^{2}$. 


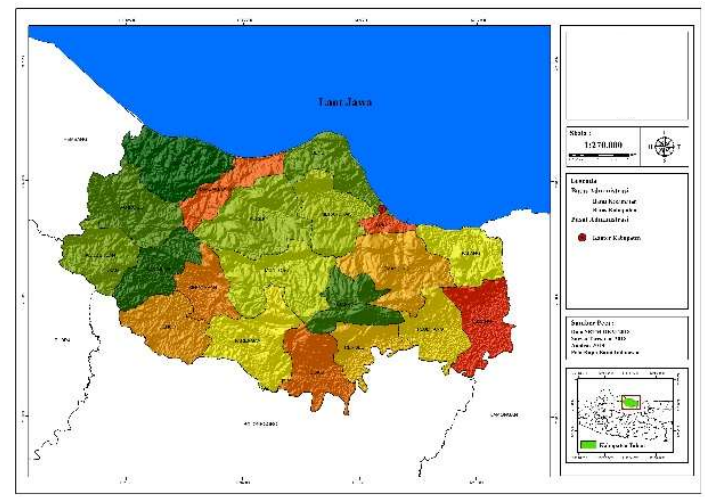

Gambar 1. Peta Administrasi Kabupaten Tuban

\section{Indeks Risiko ( $\mathrm{R}=\mathrm{H} \times \mathrm{V} / \mathrm{C})$}

\begin{tabular}{|c|c|c|c|c|c|}
\hline No. & Parameter & $\begin{array}{c}C= \\
1\end{array}$ & $\begin{array}{c}C= \\
2\end{array}$ & $\begin{array}{c}C= \\
3\end{array}$ & $\begin{array}{l}\text { Indeks } \\
\text { Risiko }\end{array}$ \\
\hline \multirow{3}{*}{1} & \multirow{3}{*}{ Banjir } & 7.5 & 3.75 & 2.5 & Rendah \\
\hline & & 30 & 15 & 10 & Sedang \\
\hline & & 67.5 & 33.75 & 22.5 & Tinggi \\
\hline \multirow{3}{*}{2} & \multirow{3}{*}{ Tanah Longsor } & 3.6 & 1.8 & 1.2 & Rendah \\
\hline & & 14.4 & 7.2 & 4.8 & Sedang \\
\hline & & 32.4 & 16.2 & 10.8 & Tinggi \\
\hline \multirow{3}{*}{3} & \multirow{3}{*}{ Gelombang Ekstrim } & 2.1 & 1.05 & 0.7 & Rendah \\
\hline & & 8.4 & 4.2 & 2.8 & Sedang \\
\hline & & 18.9 & 9.45 & 6.3 & Tinggi \\
\hline \multirow{3}{*}{4} & \multirow{3}{*}{$\begin{array}{l}\text { Cuaca Ekstrim } \\
\text { (Angin Puting } \\
\text { Beliung) }\end{array}$} & 4.8 & 2.4 & 1.6 & Rendah \\
\hline & & 19.2 & 9.6 & 6.4 & Sedang \\
\hline & & 43.2 & 21.6 & 14.4 & Tinggi \\
\hline \multirow{3}{*}{5} & \multirow{3}{*}{$\begin{array}{l}\text { Kebakaran Gedung } \\
\text { dan Permukiman }\end{array}$} & 3.6 & 1.8 & 1.2 & Rendah \\
\hline & & 14.4 & 7.2 & 4.8 & Sedang \\
\hline & & 34.8 & 17.4 & 11.6 & Tinggi \\
\hline \multirow{3}{*}{6} & \multirow{3}{*}{ Kekeringan } & 3.3 & 1.65 & 1.1 & Rendah \\
\hline & & 13.2 & 6.6 & 4.4 & Sedang \\
\hline & & 29.7 & 14.85 & 9.9 & Tinggi \\
\hline
\end{tabular}

Pembahasan penilaian risiko bencana dilakukan secara sistematis per komponen per ancaman bencana, dimulai dari ancaman bencana yang berturut-turut memiliki skor ancaman tertinggi kemudian disusul hingga ancaman yang lebih rendah dan berakhir dengan skor terendah.

\section{Sebaran Keruangan Penilaian Indeks Mapping Risiko Rencana Penanggulangan Bencana}

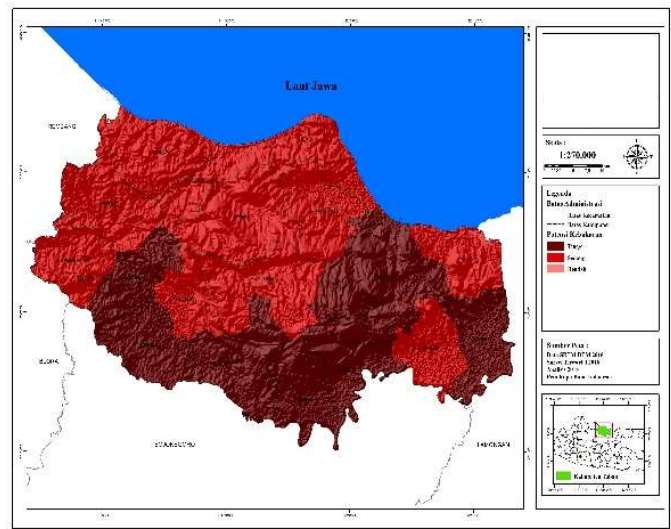

Gambar 2. Peta 'Tingkat Risiko Kebakaran

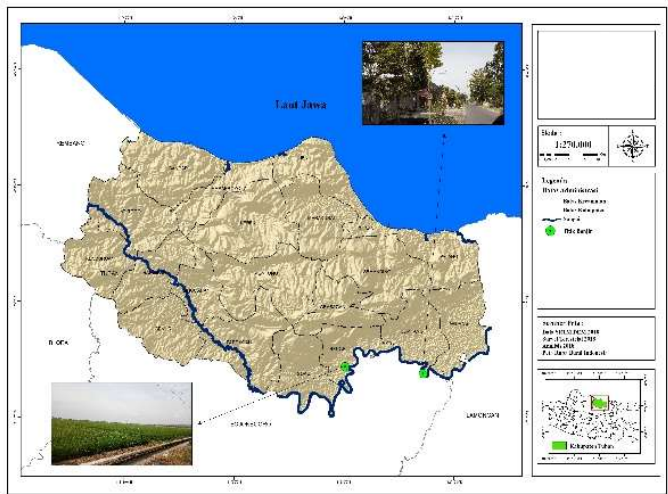

Gambar 3. Sebaran Keruangan Risiko Kebakaran

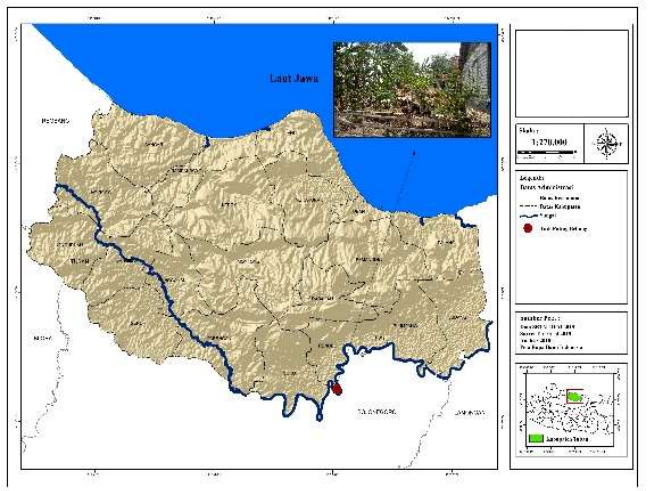

Gambar 4. Sebaran Keruangan Risiko Puting Beliung 


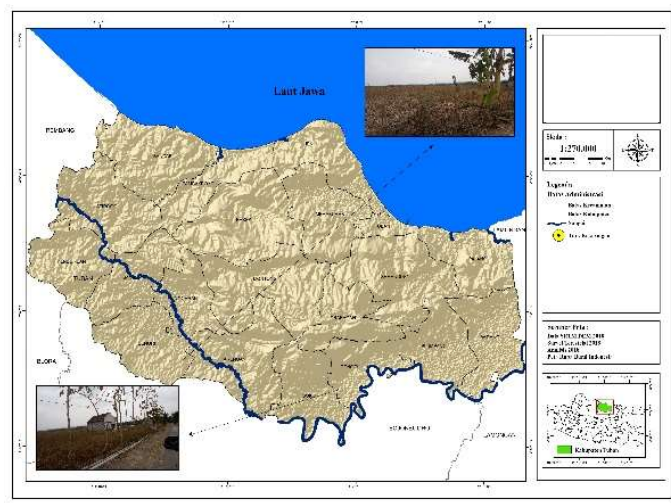

Gambar 5. Sebaran Keruangan Risiko Kekeringan

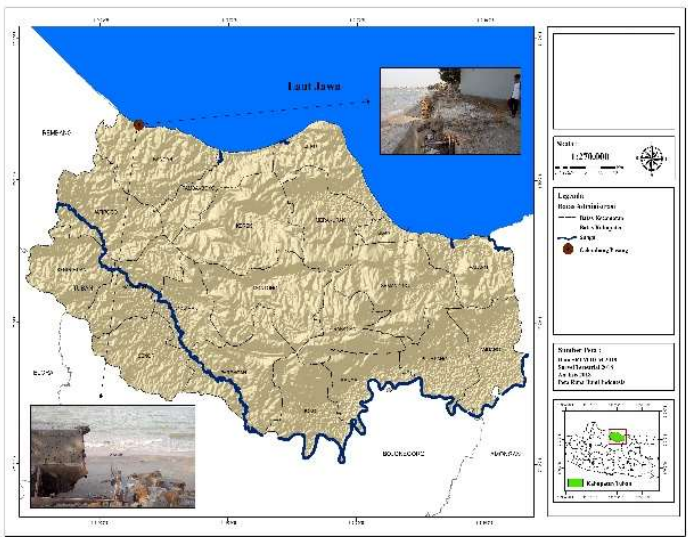

Gambar 6. Sebaran Keruangan Risiko Gelombang Ekstrim

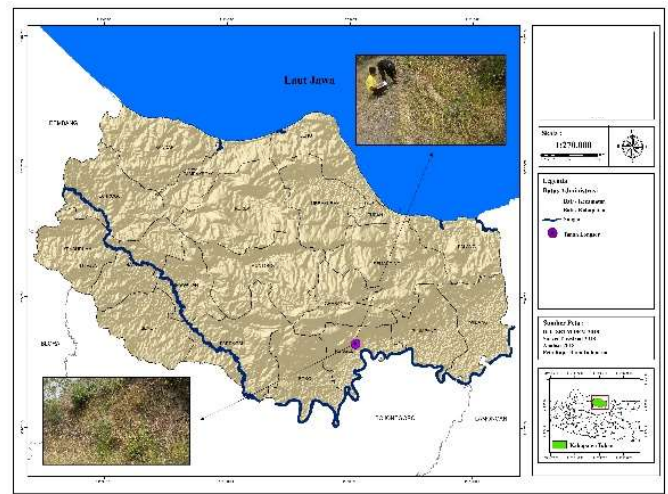

Gambar 7. Sebaran Keruangan Risiko Longsor

Sebaran keruangan risiko kejadian bencana di Kabupaten Tuban sangat bervariatif dan tersebar secara merata di wilayah administratif Kabupaten Tuban, salah satunya dapat diketahui bahwa risiko kejadian kekeringan, longsor, dan kekeringan sebagian besar tersebar di sisi selatan Kabupaten Tuban, sedangkan risiko gelombang ekstrim berpotensi pada sisi utara Kabupaten Tuban.

\section{KESIMPULAN}

Berdasarkan penelitian yang dilakukan di Kabupaten Tuban sebagai berikut :

a. Karakteristik nilai indeks risiko daerah dapat diketahui berdasarkan kejadian bencana kemudian dilakukan perhitungan secara matematis berdasarkan Peraturan Kepala Badan Nasional Penanggulangan Bencana sehingga diketemukan penggolongan tiap wilayah dan tiap jenis bencana.

b. Sebaran keruangan indeks risiko daerah di semua kecamatan yang ada di wilayah administratif Kabupaten Tuban masuk kategori zona hijau, kuning, dan merah.

\section{UCAPAN TERIMA KASIH}

Ucapan terimakasih ditujukan kepada Jurusan Perencanaan Wilayah dan Kota, Pimpinan Fakultas Teknik, Universitas PGRI Adi Buana Surabaya.

\section{DAFTAR PUSTAKA}

Badan Pusat Statistik Kabupaten Tuban Tahun 2020.

Carter, N. 1991. Disaster Management: A Disaster Manager's Handbook, ADB, Manila.

Badan Nasional Penanggulangan Bencana tentang Dokumen Indeks Risiko Bencana Indonesia Tahun 2011.

Muta'ali, L. 2012. Daya Dukung Lingkungan untuk Perencanaan Pengembangan Wilayah. Yogyakarta: Fakultas Geografi UGM.

Peraturan Kepala BNPB Nomor 02 Tahun 2012 tentang Metode Pengkajian Potensi Risiko Bencana.

Shofwan, Moch. 2018. Mitigasi Bencana Erosi dan Longsor. Sidoarjo: Meja Tamu. 
Twigg, J. 2004. Good Practice Review:Disaster Risk Reduction. Mitigation and preparedness in development and emergency programming. Humanitarian Practice Network (HPN), Overseas Development Institute, London.

UURI No. 24 Tahun 2007 tentang penanggulangan bencana, LNRI Tahun 2007 Nomor 66; TLNRI Nomor 4723

Zen, M.T. 2009. Mengelola Risiko Bencana di Negara Maritim Indonesia. Bandung: Majelis Guru Besar Institut Teknologi Bandung. 